\title{
CARACTERÍSTICAS HEMATOLÓGICAS DE TELEÓSTEOS BRASILEIROS. IV. VARIÁVEIS DO JUNDIÁ Rhamdia quelen ( PIMELODIDAE)
}

\author{
HAEMATOLOGICAL CHARACTERISTICS OF BRAZILIAN TELEOSTS.VI. \\ PARAMETERS OF JUNDIÁ Rhamdia quelen (PIMELODIDAE)
}

\author{
Marcos Tavares-Dias ${ }^{1}$ José Fernando Bibiano Melo $^{2}$ \\ Gilberto Moraes $^{3}$ Flávio Ruas de Moraes ${ }^{4}$
}

RESUMO

As características hematológicas do jundiá Rhamdia quelen Quoy \& Gaimard, 1824 (Osteichthyes: Pimelodidae), oriundo de cativeiro foram estudadas. Determinouse o valor médio da contagem de eritrócitos, taxa de hemoglobina, hematócrito, volume corpuscular médio (VCM), concentração de hemoglobina corpuscular média (CHCM) e distribuição percentual de células sangüineas de defesa orgânica. As células sangüineas de defesa orgânica (leucócitos e trombócitos) foram identificadas e caracterizadas morfologicamente. Trombócitos e linfócitos foram as células sangüineas de defesa orgânica mais freqüente nas extensões sangüíneas do $\boldsymbol{R}$. quelen. A análise de regressão mostrou correlação linear negativa entre o percentual de trombócitos e linfócitos. Os resultados deste estudo fornecem valores sangüineos normais em $\boldsymbol{R}$. quelen, em cultivo intensivo, que poderão servir de comparação com dados dessa espécie em outras situações de cultivo.

Palavras-chave : hematologia, leucócitos, peixe de água doce, Rhamdia quelen, sangue.

\section{SUMMARY}

The present paper describes haematological characteristics of jundiá Rhamdia quelen Quoy \& Gaimard, 1824 (Osteichthyes: Pimelodidae), reared in captivity. The average values of red blood cells count, hematocrit, hemoglobin rate, mean corpuscular volume $(\mathrm{MCV})$, mean corpuscular hemoglobin concentration $(\mathrm{MCHC})$ and defense blood cells (leukocytes and thrombocytes), were determined. Identification and morphology of organic defense blood cells were reported. Thrombocytes and lymphocytes were the most frequent cells in slides blood of $\boldsymbol{R}$. quelen. Linear regression analysis showed negative correlation between thrombocytes and lymphocytes percentual. The present results furnish normal blood values of $\boldsymbol{R}$. quelen reared intensively, that assist in comparison to the other culture conditions.

Key words: blood, freshwater fish, haematology, leucocytes, Rhamdia quelen.

\footnotetext{
${ }^{1}$ Laboratório de Patologia de Organismos Aquáticos, Centro de Aqüicultura (CAUNESP) da Universidade Estadual Paulista (UNESP). Via de Acesso Professor Paulo Donato Castellane, s/n, 14870-000, Jaboticabal, São Paulo, Brasil. E-mail: matavares@caunesp.unesp.br. Autor para correspondência.

${ }^{2}$ Laboratório de Bioquímica Adaptativa, Universidade Federal de São Carlos (UFSCar). Rodovia Washington Luiz, Km 235, São Carlos, São Paulo, Brasil. E-mail: pgaucho@iris.ufscar.br

${ }^{3}$ Laboratório de Bioquímica Adaptativa, UFSCar. Rodovia Washington Luiz, Km 235, São Carlos, São Paulo, Brasil.

${ }^{4}$ Laboratório de Patologia de Organismos Aquáticos, Centro de Aqüicultura da UNESP. Via de Acesso Professor Paulo Donato Castellane, s/n, 14870-000, Jaboticabal, São Paulo, Brasil.
} 


\section{INTRODUÇÃO}

O gênero Rhamdia é formado por 11 espécies, dentre as quais o Rhamdia quelen que possui 49 sinonímias (SILFVERGRIP, 1996). Esse siluriforme é encontrado desde o centro da Argentina até o sul do México. Seu cultivo está se intensificando no sul do Brasil, pois sua reprodução induzida apresenta bons resultados e altas taxas de fecundação (GOMES et $\boldsymbol{a l}$., 2000). A maturidade sexual é atingida com um ano de idade em ambos os sexos, quando os machos com $13,4 \mathrm{~cm}$ iniciam o processo de maturação gonadal e as fêmeas com $16,5 \mathrm{~cm}$ (NARAHARA et al., 1985). Segundo RADÜNZ NETO (1981), este peixe possui boa aceitação no mercado consumidor, boa produtividade em açudes e apresenta alto potencial de comercialização, tornando-se uma ótima opção para o fomenta da piscicultura. Devido a grande importância comercial desse teleósteo, conhecido como bagre sul americano, são ainda necessários maiores estudos relacionados às suas características biológicas, principalmente hematológicas. Nesse tocante, a literatura faz referências ao eritrograma e leucograma de Rhamdia hilarii, sem descrição do local de captura dos peixes (FORESTI et al., 1977) e de jundiás do Rio Jaguari, São Paulo (KAVAMOTO et al., 1983). Zuim et al. (1986) descrevem as alterações do hematócrito e do volume dos eritrócitos em ambos os sexos $\boldsymbol{R}$. quelen durante a maturação gonadal. O presente trabalho teve como objetivo contribuir com a descrição dos valores médios do eritrograma, a caracterização e contagem diferencial de células sangüíneas de defesa orgânica (leucócitos e trombócitos) em jundiás Rhamdia quelen, oriundos de cultivo intensivo.

\section{MATERIAL E MÉTODOS}

Espécimes de jundiá Rhamdia quelen foram obtidos no Setor de Piscicultura da Universidade Federal de Santa Maria, Rio Grande do Sul, através da reprodução induzida. Utilizou-se extrato hipofisário de carpas, com dosagem única de $4 \mathrm{mg} / \mathrm{kg}$ de peso vivo para fêmeas e $2 \mathrm{mg} / \mathrm{kg}$ para machos. Os alevinos obtidos foram estocados em tanques de terra de $1.000 \mathrm{~m}^{2}$, no Centro de Aquicultura da Universidade Estadual Paulista (CAUNESP), Campus de Jaboticabal, São Paulo. Os peixes foram alimentados com ração comercial contendo $34 \%$ de proteína bruta e $3.500 \mathrm{kcal}$ de energia bruta até atingirem 10 meses de idade. Ao fim deste período, 60 espécimes com tamanho médio de $16,0 \mathrm{~cm}$ e peso médio de $44,0 \mathrm{~g}$ foram submetidos ao exame hematológico.
De cada peixe foi colhida uma alíquota de sangue por punção do vaso caudal, com auxílio de seringas de $1 \mathrm{~mL}$ previamente heparinizadas. Esse sangue destinou-se às determinações da contagem de eritrócitos em câmara de Neubauer, taxa de hemoglobina (COLLIER, 1944), hematócrito (GOLDENFARB et $\boldsymbol{a l}$.,1971) e contagem diferencial de células sangüíneas de defesa orgânica (leucócitos e trombócitos). Para contagem diferencial de células sangüíneas de defesa orgânica, foram preparadas extensões sanguiíneas, e adotou-se a metodologia e nomenclatura sugerida por TAVARES-DIAS $\boldsymbol{e t} \boldsymbol{a l}$. (1999a,b; 2000a,b). De posse dos resultados da contagem de eritrócitos, taxa de hemoglobina e hematócrito foram calculados: o volume corpuscular médio (VCM) e a concentração de hemoglobina corpuscular média (CHCM), segundo WINTROBE (1934). Os resultados encontrados para contagem diferencial de células sangüíneas de defesa orgânica foram analisados por regressão linear e teste $t$, a $5 \%$ de probabilidade (BANZATO \& KRONKA, 1995).

\section{RESULTADOS}

Os valores médios e a amplitude de variação da contagem de eritrócitos, hemoglobina, hematócrito, VCM e CHCM em R. quelen estão relacionados na tabela 1 . Verifica-se que o número de eritrócitos variou de 1,55 a 2,92 × $10^{6} / \mu \mathrm{L}$, a hemoglobina de 4,95 a 9,09 g/dL, hematócrito de 17,00 a $34,00 \%$, VCM de 87,82 a $219,35 \mathrm{fL}$ e o CHCM de 20,24 a 35,91g/dL.

Foram identificados e caracterizados na contagem diferencial de células sangüíneas de defesa orgânica em jundiá $\boldsymbol{R}$. quelen: trombócitos, linfócitos, neutrófilos, monócitos, células granulocíticas especiais (CGE), eosinófilos e células imaturas (Tabela 1). O percentual de trombócitos apresentou correlação negativa $(\mathrm{P}<0,05)$ com o percentual de linfócitos (Figura 1).

Os trombócitos são células predominantemente elípticos, ocasionalmente arredondadas, de citoplasma hialino sem granulações e núcleo fusiforme. Os neutrófilos são predominantemente arredondados, de citoplasma basofílico e grânulos acidófilos fracamente corados pelo corante ácido ou básico usado. O núcleo tem forma de bastonete ou ocasionalmente segmentado, em geral excêntrico, sendo a cromatina nuclear compacta e sem nucléolo visível. As células granulocíticas especiais (CGE) são grandes e muito semelhantes aos neutrófilos, com citoplasma que se cora fracamente pelo corante ácido- básico. O núcleo é pequeno, excêntrico, contém cromatina 
Tabela 1 - Variáveis eritrocitárias e distribuição percentual de células sangüíneas de defesa orgânica em jundiá Rhamdia quelen ( $\mathrm{n}=60$ ) cultivado no Centro de Aqüicultura da Unesp (CAUNESP) - Jaboticabal, São Paulo.

\begin{tabular}{lcc}
\hline Parâmetros & Valores médios & Amplitude de variação \\
\hline Eritrócitos $(\mathrm{x} \mathrm{10} / \mu \mathrm{L})$ & $1,95 \pm 0,40$ & $1,55-2,92$ \\
Hemoglobina $(\mathrm{g} / \mathrm{dL})$ & $6,73 \pm 1,15$ & $4,95-9,09$ \\
Hematócrito $\%$ ) & $26,50 \pm 5,30$ & $17,00-34,00$ \\
VCM (fL) & $139,03 \pm 34,78$ & $87,82-219,35$ \\
CHCM (g/dL) & $25,94 \pm 4,73$ & $20,24-35,91$ \\
Trombócitos (\%) & $78,42 \pm 8,23$ & $40,00-91,00$ \\
Linfócitos (\%) & $11,61 \pm 6,57$ & $1,00-38,00$ \\
Neutrófilos (\%) & $6,02 \pm 3,33$ & $1,00-16,00$ \\
C.G.E. (\%) & $1,24 \pm 1,96$ & $1,00-9,00$ \\
Monócitos (\%) & $1,13 \pm 1,09$ & $0,00-4,00$ \\
Eosinófilos (\%) & $0,02 \pm 0,14$ & $0,0-1,00$ \\
Células imaturas (\%) & $1,69 \pm 1,66$ & $0,00-8,00$ \\
\hline
\end{tabular}

C.G.E. $=$ Célula granulocítica especial

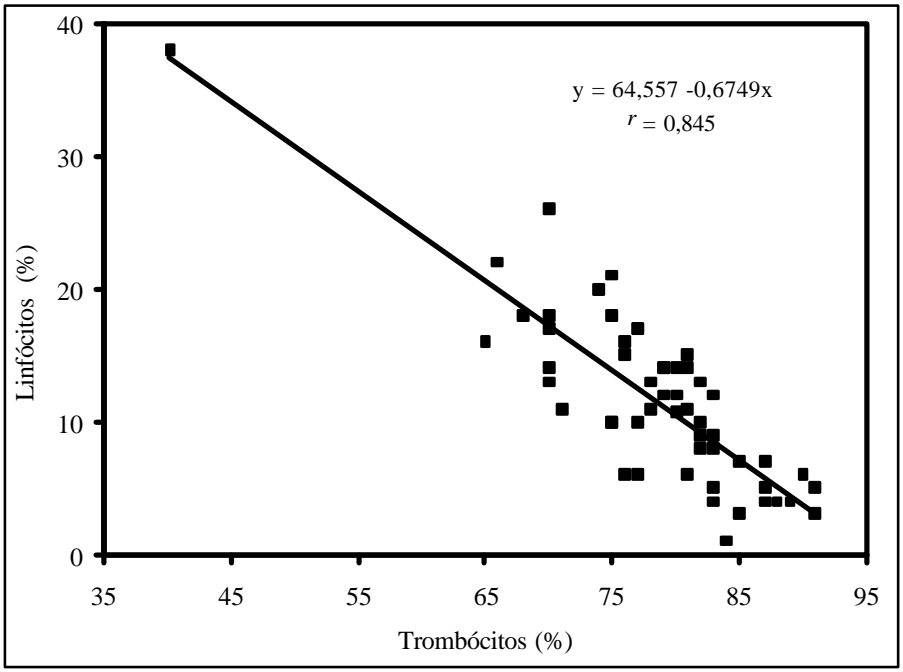

Figura 1 - Relação entre o percentual de trombócitos e linfócitos em $\boldsymbol{R}$. quelen.

densa e não se observou a presença de nucléolo. Os linfócitos são células predominantemente arredondadas e de tamanho variado, têm citoplasma basofílico e sem granulações visíveis. O núcleo possui forma arredondada, cromatina densa, sendo elevada a sua relação com o citoplasma. Os monócitos são células predominantemente grandes, de forma arredondada e citoplasma basofílico fracamente corado pelo corante ácido ou básico usado. O núcleo é freqüentemente excêntrico, geralmente alongado, ocasionalmente esférico. Os eosinófilos são células relativamente pequenas e predominantemente arredondadas. O citoplasma é completamente ocupado por grânulos acidófilos, que se coram de róseo-alaranjado. O núcleo é geralmente excêntrico, com cromatina compacta. As células imaturas variam de tamanho, podendo assemelhar-se aos linfócitos ou monócitos. A diferença é que apresentam citoplasma de coloração intensamente basofílico (Figura 2).

\section{DISCUSSÃO}

As enfermidades, de modo geral, estão relacionadas às alterações do hemograma nos animais e no homem. Por isso o quadro hematológico de diferentes peixes e condições de criação vem sendo estudado (TAVARES-DIAS $\boldsymbol{e t}$ al., 2000c). O estudo da hematologia em peixes ainda contribui para a compreensão da fisiologia comparativa, relação filogenética, condições alimentares e outros parâmetros ecológicos (LARSSON et al., 1976).

Em $\boldsymbol{R}$. quelen jovens estudadas no presente trabalho, os valores de eritrócitos são superiores aos descritos para jundiás adultos de ambos os sexos, assim como para os bagres americano e africano (Tabela 2). $\mathrm{O}$ hematócrito é inferior ao descrito para o mesmo bagre sul americano $\boldsymbol{R}$. quelen) e bagre $\boldsymbol{C}$. isheriensis, porém superior ao do bagre americano I. punctatus. Entretanto, o número de eritrócitos, hemoglobina e $\mathrm{CHCM}$ são mais próximos aos valores relatados por FORESTI et al. (1977) (Tabela 2). Todavia, além de tratarem-se de espécies diferentes e/ou mesma espécie coletada em ambientes diferentes, deve ser considerado que indivíduos de tamanhos diferentes liberam energia em quantidade também diversa de acordo com o seu tamanho corporal, podendo interferir com o seu quadro hematológico (TAVARES-DIAS $\boldsymbol{e t} \boldsymbol{a l}$., 2000b). Outros fatores como o estado nutricional, sazonalidade, maturação gonadal, sexo e variação genética também podem influenciar significativamente as variáveis hematológicas (KORI-SIAKPERE, 1985). Há ainda, diferenças na metodologia de colheita de sangue, quanto ao tipo de anticoagulante utilizado, as quais também podem atuar como fonte de variação de resultados hematológicos em peixes. TAVARES-DIAS \& SANDRIN (1998) demonstraram que o hematócrito e taxa de hemoglobina do sangue heparinizado são maiores se comparados ao encontrado no sangue colhido com EDTA, para um mesmo animal.

Neste ensaio, as células sangüíneas de defesa orgânica (trombócitos, linfócitos, neutrófilos, monócitos, células granulocíticas especiais) 


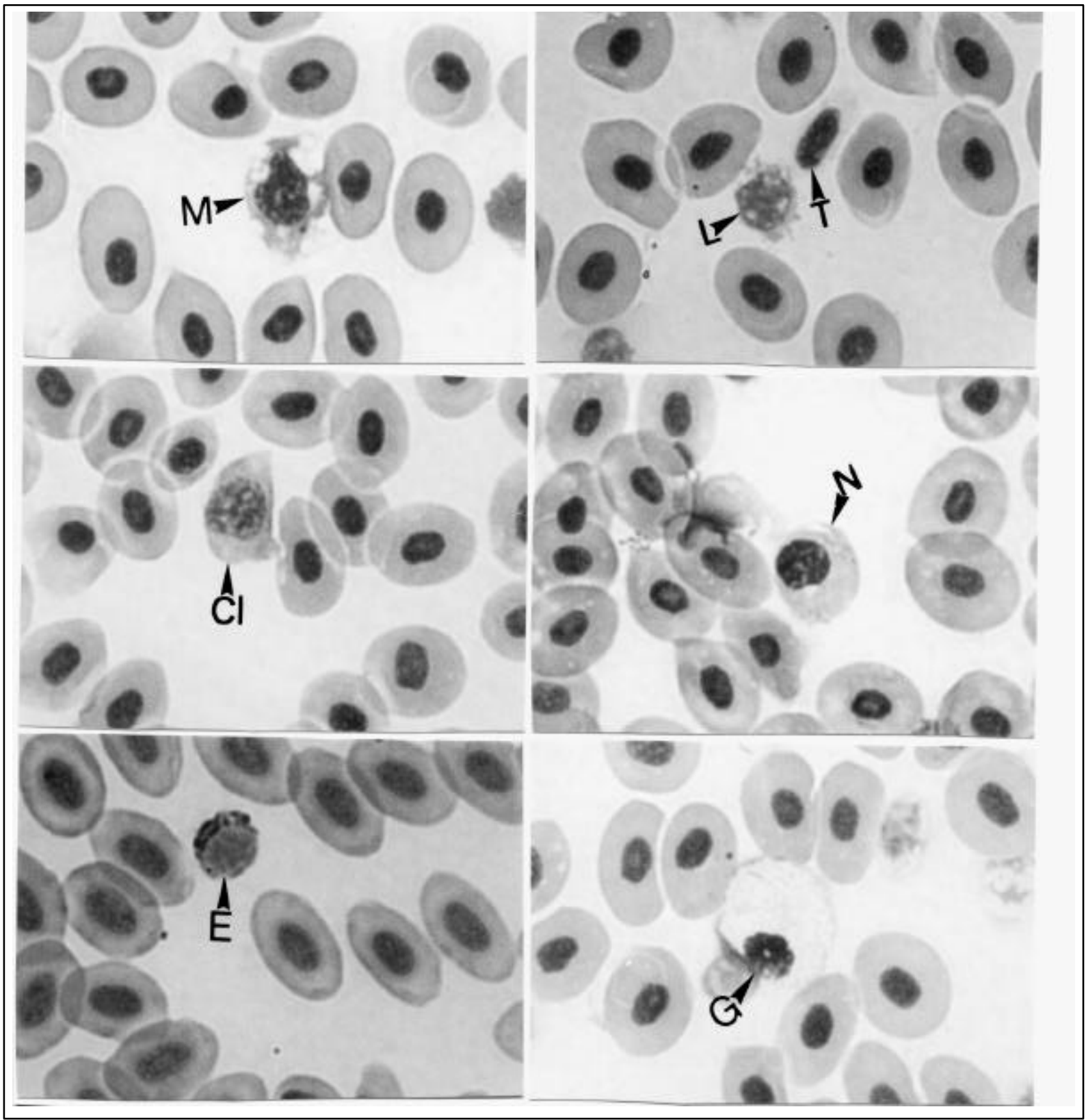

Figura 2 - Células sanguiíneas com função de defesa orgânica em $\boldsymbol{R}$. quelen. Trombócito (T), Neutrófilo (N), Célula granulocítica especial (G), Linfócito (L), Monócito (M) e Célula imatura (CI). Aumento 2230 x. Coloração: ROSENFELD.

identificadas em $\boldsymbol{R}$. quelen, são morfologicamente similares as descritas em curimbatá Prochilodus scrofa (RANZANI-PAIVA \& GODINHO 1983), Pirapitinga-do-sul Brycon sp. (RANZANI-PAIVA, 1991), matrinxã Brycon cephalus (TAVARESDIAS et al., 1999b), híbrido tambacu (TAVARESDIAS et al., 2000a). Todavia, em $\boldsymbol{R}$. quelen monócitos e neutrófilos apresentam pouca afinidade tintatorial ao corante ácido-básico utilizado, à semelhança do que já foi observado, anteriormente nesse laboratório, em B. cephalus, tilápia-do-Nilo
Oreochromis niloticus, Tilapia rendalli e tilápia vermelha da Flórida. Porém, isso não ocorre em pacu Piaractus mesopotamicus, tambaqui Colossoma macropomum, híbrido tambacu, carpacomum Cyprinus carpio e piauçú Leporinus macrocephalus.

Há necessidade de identificação das células sangüíneas de defesa orgânica de cada espécie de teleósteo em condições de normalidade para entendimento do comportamento das populações celulares na vigilância de processos 
mórbidos (TAVARES-DIAS et al., 2000c). O percentual de cada célula sangüínea de defesa orgânica em $\boldsymbol{R}$. quelen varia consideravelmente quando comparado ao I. punctatus (CANNON et al., 1980; BREAZILE et al., 1982; ELLSAESSER et $\boldsymbol{a l}$., 1985) e Clarias gariepinus (BOOMKER, 1981). Todavia, as células sangüíneas de defesa orgânica apresentam variação interespecífica (BOOMKER, 1981).

Neste trabalho, trombócitos e linfócitos foram as células de defesa orgânica mais frequientes nas extensões sangüíneas e apresentaram correlação negativa entre si, à semelhança do que ocorre com o híbrido tambacu (TAVARES-DIAS $\boldsymbol{e t}$ al., 2000a) e O. niloticus (TAVARES-DIAS \& FAUSTINO, 1998; TAVARES-DIAS $\boldsymbol{e t} \boldsymbol{a l}$., 2000c). Estudos similares também relatam elevada ocorrência de trombócitos e linfócitos em $\boldsymbol{I}$. punctatus (CANNON et al., 1980; BREAZILE $\boldsymbol{e t}$ al., 1982; ELLSAESSER et al., 1985). Porém, no bagre africano, C. gariepinus (BOOMKER, 1981) trombócitos e neutrófilos são mais frequientes.

Leucócitos imaturos (células imaturas) foram observados nas extensões sangüíneas de jundiá $\boldsymbol{R}$. quelen à semelhança do que ocorre em Salmo trutta (BAXHALL \& DAISLEY, 1973), $\boldsymbol{P}$. mesopotamicus, C. macropomum e Prochilodus scrofa (RANZANI-PAIVA et al., 1998/1999). As características tintatorias dessas células são similares às descritas por (BAXHALL \& DAISLEY, 1973). Muito pouco se conhece, até o presente momento, sobre a origem e o desenvolvimento dos trombócitos e leucócitos em peixes, embora algumas idéias vêm sendo propostas desde o início do século passado. Todavia, os dados obtidos através dos estudos da hematologia e/ou dos órgãos hematopoéticos ainda são pouco conclusivos.

\section{REFERÊNCIAS BIBLIOGRÁFICAS}

BANZATO, D.A., KRONKA, S.N. Experimentação agrícola. 3 ed. Jaboticabal : FUNEP, 1995. 247p.

BLAXHALL, P.C., DAISLEY, K.W. Routine hematological methods for use with fish blood. Journal of Fish Biology, London, v.5, p.771-781, 1973.

BOOMKER, J. The haemocytology and histology of the haemopoietic organs of south African freshwater fish. III. The leucocytes, plasma cells and macrophages of Clarias gariepinus and Sarotherodon mossambicus. Onderstepoort Journal of Veterinary Research, Onderstepoort, v.48, p.185-193, 1981
Variáveis eritrocitárias do bagre americano (Ictalurus punctatus), bagre africano (Clarias isheriensis) e bagre sul americano (Rhamdia quelen).

\begin{tabular}{|c|c|c|c|c|c|}
\hline spécies & $\begin{array}{c}\text { Eritrócitos } \\
\left(10^{6} / \mu \mathrm{L}\right)\end{array}$ & $\begin{array}{l}\text { Hemoglobina } \\
\text { (g/dL) }\end{array}$ & $\begin{array}{c}\text { Hematócrito } \\
(\%)\end{array}$ & $\begin{array}{l}\mathrm{VCM} \\
(\mathrm{fL})\end{array}$ & $\begin{array}{c}\text { CHCM } \\
(\mathrm{g} / \mathrm{dL})\end{array}$ \\
\hline $\begin{array}{l}\text { punctatus } \\
\text { et al., 1982) }\end{array}$ & 1,610 & 3,96 & 22,70 & 138,80 & 16,50 \\
\hline 2000) punctatus & 1,550 & 5,90 & 23,90 & - & - \\
\hline $\begin{array}{l}\text { isheriensis } \\
\text { PERE, 1985) }\end{array}$ & 1,550 & 14,56 & 31,62 & 207,35 & 46,47 \\
\hline tal., 1977) & 1,700 & 7,44 & 30,14 & 241,94 & 24,92 \\
\hline $\begin{array}{r}\text { quelen } \\
\text { TO et al., 1983) }\end{array}$ & 1,585 & 11,43 & 35,19 & 23,11 & 32,98 \\
\hline elen & 1,950 & 6,73 & 26,50 & 139,03 & 25,94 \\
\hline
\end{tabular}

BREAZILE, J.E., ZINN, L.L., YAUK, J.C., et al. A study of haematological profiles of channel catfish, Ictalurus punctatus (Rafinesque). Journal of Fish Biology, London, v.21, p.305-309, 1982.

CANNON, M.S., MOLLERNHAUER, H.H., EURELL, T.E., $\boldsymbol{e}$ al. An ultrastructural study of the leukocytes of the channel catifish, Ictalurus punctatus. Journal of Morphology, New York, v.164, p.1-23, 1980.

COLLIER, H.B. The standardization of blood haemoglobin determinations. Canadian Medical Association Journal,Vancouver, v.50, p.550-552, 1944.

ELLSAESSER, C.F., MILLER, N.W., CUCHENS, M.A., $\boldsymbol{e}$ t al. Analysis of channel catfish peripheral blood leucocytes by bright-field microscopy and flow cytometry. Transactions of the American Fisheries Society, Bethesda, v.114, p.279285, 1985.

FORESTI, F., VOLPATO, G.L., GARCIA, E.M., et al. Medidas de alguns parâmetros morfológicos e fisiológicos do sangue de bagre (Rhamdia hilarii Valenciannes, 1840) (Pisces: Pimelodidae). Ciência e Cultura, Rio de Janeiro, v.29, n.7, 580, 1977.

GOLDENFARB, P.B., BOWYER, F.P., HALL, E., et al. Reproducibility in the hematology laboratory: the microhematocrit determination. American Journal of Clinical Pathology, New York, v.56, p.35-39, 1971.

GOMES, L.C., GOLOMBIESKI, J.I.,GOMES, A.R.C., et al. Biologia do jundiá Rhamdia quelen (Teleostei, Pimelodidae) - Revisão bibliográfica. Ciência Rural, Santa Maria, v.30, n.1, p.179-185, 2000.

KAVAMOTO, E.T., RANZANI-PAIVA, M.J., TOKUMARU, M. Estudos hematológicos em "bagre" Rhamdia hilarri (Val.1840) teleósteos, no estádio de desenvolvimento gonadal maduro. Boletim do Instituto de Pesca, São Paulo, v.10, n.único, p.53-60, 1983.

KORI-SIAKPERE, O. Haematological characteristics of Clarias isheriensis Sydenham. Journal of Fish Biology, London, v.27, p.259-63, 1985.

LARSON, A., JOHANSSON-SJOBECK, M.J., FANGE, R. Comparative study of some haematological and biochemical blood parameters in fishes from the Skagerrak. Journal of Fish Biology, London, v.9, p.425-440, 1976. 
LIM, C., KLESIUS, P.H., LI, M.H., ROBINSON, E.H. Interaction between dietary levels of iron and vitamin $\mathrm{C}$ on growth, hematology, immune response and resistance of channel catfish (Ictalurus punctatus) to Edwardsiella ictaluri challenge. Aquaculture, New York, v.185, p.313327, 2000.

NARAHARA, M.Y., GODINHO, H.M., ROMAGOSA, E. Estrutura da população de Rhamdia hilarii (Valenciennes, 1840) (Osteichthyes, Siluriformes, Pimelodidae). Boletim do Instituto de Pesca, São Paulo, v.12, n.3, p.123-137, 1985.

RADÜNZ NETO, J. Desenvolvimento de técnicas de reprodução e manejo de larvas de jundiá Rhamdia quelen . Santa Maria, 1981. 77p. Dissertação (Mestrado em Zootecnia) - Curso de Pós-graduação em Zootecnia. Universidade Federal de Santa Maria, 1981.

RANZANI-PAIVA, M.J.T. Características sangüíneas da pirapitinga do sul, Brycon sp, sob condições experimentais de criação intensiva. Brazilian Journal of Veterinary Research and Animal Science, São Paulo, v.28, n.2, p.141$153,1991$.

RANZANI-PAIVA, M.J.T., GODINHO, H.M. Sobre células sanguíneas e contagem diferencial de leucócitos e eritroblastos em curimbatá, Prochilodus scrofa Steindacher, 1881 (Osteichthyes, Cypriniformes, Prochilodontidae) Revista Brasileira de Biologia, Rio de Janeiro, v.43, n.4, p.331-338, 1983

RANZANI-PAIVA, M.J.T., SALLES, F.A., EIRAS, J.C., et al Análise hematológica de curimbatá (Prochilodus scrofa), pacu (Piaractus mesopotamicus) e tambaqui (Colossoma macropomum ) das estações de piscicultura do Instituto de Pesca, Estado de São Paulo. Boletim do Instituto de Pesca, São Paulo, v.25, p.77-83, 1998/1999.

SILFVERGRIP, A.M.C. A sistematic revision of the neotropical catfish genus Rhamdia (Teleostei, Pimelodidae). Stockholm : Departament of Zoology, Stockholm University and Departement of Vertebrate Zoology, Swedish Museum of Natural History , 1996. 156p.

TAVARES-DIAS, M., FAUSTINO, C.D. Parâmetros hematológicos da tilápia-do-Nilo Oreochromis niloticus (Cichlidae) em cultivo extensivo. Jaboticabal, v.14, n.3, p.254-263,1998.
TAVARES-DIAS, M., SANDRIN. E.F.S. Influence of anticoagulants and blood storage on hematological values in tambaqui, Colossoma macropomum. Acta Scientiarum, Maringá, v.20, n.2, p.151-155, 1998.

TAVARES-DIAS, M., TENANI, R.A., GIOLI, L.D., $\boldsymbol{e t} \boldsymbol{a l}$. Características hematológicas de teleósteos brasileiros. II. Parâmetros sanguiíneos do Piaractus mesopotamicus Holmberg, 1887 (Osteichthyes: Characidae) em policultivo intensivo. Revista Brasileira de Zoologia, Curitiba, v.16, n.2, p.423-431,1999a.

TAVARES-DIAS, M., FRASCÁ-SCORVO, C. M.D., MORAES, F.R., et al. Características hematológicas de teleósteos brasileiros. IV. Parâmetros eritroleucométricos, trombométricos e glicemia do matrinxã Brycon cephalus Günther, 1869 (Osteichthyes: Characidae). Ars Veterinaria, Jaboticabal, v.15, n.3, p.149-153, 1999b.

TAVARES-DIAS,M., SCHALCH, S.H.C., MARTINS, M.L., et al. Haematological characteristics of Brazilian teleosts. III. Parameters of the hybrid tambacu (Piaractus mesopotamicus $\mathrm{x}$ Colossoma macropomum) (Osteichthyes: Characidae). Revista Brasileira de Zoologia, Curitiba, v.17, n.4, p.899926, 2000a.

TAVARES-DIAS, M., FRASCÁ-SCORVO, C.M.D., NOVATO, P.FC., et al. Hematological characteristics of hybrid Florida red tilapia, Oreochromis urolepis hornorun $\mathrm{x} \boldsymbol{O}$. mossambicus under intensive rearing. In: PROCEEDINGS INTERNATIONAL SIMPOSIUM ON TILAPIA AQUACULTURE, 5, 2000, Rio de Janeiro. Anais... Rio de Janeiro : Fitzmmons, K., Carvalho Filhos, J. (Ed.), 2000b. p.533-541.

TAVARES-DIAS,M., SCHALCH, S.H.C., MARTINS, M.L., et al. Características hematológicas de Oreochromis niloticus (Osteichthyes: Cichlidae) cultivadas intensivamente em "Pesque-Pague" do Município de Franca, São Paulo, Brasil. Ars Veterinaria, Jaboticabal, v.16, n.2, 76-82, 2000c.

WINTROBE, M.M. Variations on the size and haemoglobin content of erythrocytes in the blood of various vertebrates. Folia Haematologica, Leipzig, v.51, p.32-49, 1934.

ZUIM, S.M.F., SANTOS, H.S.L.,OLIVEIRA, C., et al. Influências do sexo e do estádio sexual sobre parâmetros hematológicos em Rhamdia hilarii (bagre). I. Série vermelha. In: SIMPÓSIO BRASILEIRO DE AQUICULTURA, 5, 1986, Cuiabá. Anais... Cuiabá : Abraq, 1986. p.81-89. 